\title{
The interpretative particularities of the copy of Beethoven's Sixth Symphony in National and University Library in Ljubljana
}

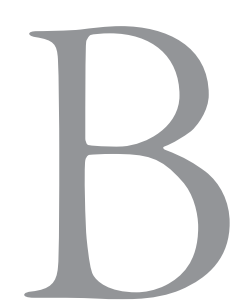

eethoven wrote his Sixth Symphony in I808. According to the exhaustive information in the preface to Bärenreiter's edition of the symphony, ${ }^{\mathrm{T}}$ the composer had already occupied himself with thoughts of the symphony in $\mathrm{I} 803$ and finished the symphony five years later. He performed it in the famous academy on 22 December 1808 , in an unheated auditorium of the 'Theater an der Wien', where his Fifth Symphony also sounded for the first time on a mammoth programme. Among others, Beethoven also appeared in the event as a soloist in his piano concert. The researchers believe that the 'Ljubljana' authorised transcript of this symphony had served as the score from which Beethoven had conducted his Sixth Symphony in this concert.

Beethoven's manuscript of the Sixth Symphony is preserved, but the composition is practically impossible to perform from it, since it has too many abbreviations, only indicated bars, and corrections, which makes the transparency of the compositional matter very hard. Two transcripts of the score were made in autumn 1808 by Beethoven's copyist Joseph

I Barry Cooper, Introduction to Beethoven's $6^{\text {th }}$ Symphony (Bärenreiter, 200I).
Klumpar, ${ }^{2}$ and found within them are numerous corrections by the composer, written in his characteristic reddish pencil. ${ }^{3}$ It should be mentioned that, in the 'Ljubljana' transcript, the $4^{\text {th }}$ movement of the symphony was written by another copyist.

The great value of the manuscript copy in the National and University Library in Ljubljana (NUK) lies above all in the fact that the author had entered his remarks into it. This naturally means that Beethoven had examined the score, which had likely served him at the performance in Vienna and was later sent to Ljubljana, in detail and added practical remarks. There is yet another detail that must not be overlooked: given the poorly legible manuscript of the author, Klumpar's transcript may by itself be perceived as an authentic testimony of the author's intentions.

There are no significant differences between both transcripts of the score. The copyist Klumpar was considered a highly reliable and atten-

2 Sieghard Brandenburg, Sechste Symphonie F-Dur Opus 68. Sinfonia pastorale. Faksimile nach dem Autograph BH 64 im Beethoven-Haus Bonn mit einem Kommentar von Sieghard Brandenburg (Bonn: Beethoven-Hauses, 2000).

3 Current computer technology enables a forensically reliable oversight of all the places where Beethoven had touched his manuscript or with his reddish pencil, or upon the corrections of both transcripts. 
tive reader of the score, ${ }^{4}$ who had, in transcribing, several times asked Beethoven for clarifications regarding unclear or omitted spots and certain probably incorrect notes. In the note record itself, both copies are identical; the differences in the notation of accidences between the manuscript and its copy in NUK originate, perhaps, merely from the copyist's inconsistency in transcribing the note text. Beethoven's manuscript also leaves doubts sometimes, mostly because of his personality, inclined to an irritable temper.

Two types of accidences are found in Beethoven's scores: dots and wedges. 5 The latter are notated by Beethoven in a simple vertical line, while the dot is frequently very elongated. Thus, it is often hard to decide on what Beethoven had had in mind while notating articulations. When he notated dots, these often resemble wedges.

In time, two types of notating accidences have established itself in print: at the end of the $19^{\text {th }}$ and until approximately the 1970 , the belief that it was not possible to write dots with a quill was common. Experiments have shown that this is not the case, but the result of this incorrect assumption was a universal notating of only dots above the notes. The newer editions of Beethoven's works (Bärenreiter, Henle), however, have gone to the other extreme: instead of the former dots, wedges are now exclusively notated as accidences, which makes the performance very striking and essentially rough. In regard to Beethoven's Sixth Symphony, both of Klumpar's transcripts are a starting point for a sort of a middle way (obviously after a thorough reflection and consultations)

4 Brandenburg, Sechste Symphonie F-Dur Opus 68.

$5 \quad$ In German 'die Keile'; in Slovenian, while the expression 'kajla' prevailed in the professional language, it is a rough expression and has the character of expressing oneself in a dialect.

\section{Accidences $^{6}$}

At the beginning of the $19^{\text {th }}$ century, we witness ever larger demands for an authentic interpretation of the music text as possible, and with it, the tendencies increased toward as high an accuracy of the music record as possible. This referred both to the tempo and the articulation. Beethoven was in the lead in these demands. He was the first one no longer satisfied with Quantz's steady expressions for the tempos Adagio, Allegretto, Allegro and Presto, but had exceptionally expanded the vocabulary for the desired tempo and character of the composition. At the same time he was the initiator of giving effect to mechanical tempo control, which later resulted in Mälzel's metronome.

He was just as persistent and innovative in view of the articulation. In his well-known letter of $\mathrm{I} 825$ to Karl Holz, Beethoven demanded a clear distinction between dots and wedges in the $2^{\text {nd }}$ movement of his Seventh Symphony ${ }^{7}$. A clear distinction between the two marks is already noticed in his First Symphony and continues in all his later symphonic works. However, it needs noting that only wedges (sic!) are found in the first printed orchestra materials that Beethoven was able to examine (e.g., the First Symphony, and also the treated Sixth Symphony). It may have been the manner of marking accidences at the time. The publisher Cianchettini \& Sperati in London paid regard to the differences in their notation in the printing of Beethoven's First Symphony in I808, and the first print of the Sixth Symphony by the publisher Breitkopf \& Härtel offers dots exclusively as the accidences. The confusion, or uncertainty, in the noting of Beethoven's works, is therefore obvious.

Considered the principle of differentiating between dots and wedges is the famous saying by Prof. Hans Swarowski: 'A wedge adds weight to the note, while a dot takes the weight away from it'. However, another

6 The terminus 'accidence' is not used here in the narrow musical-theoretical sense, but marks all the characters and other semantic signs that interpretatively define a note more precisely.

S Sieghard Brandenburg, ed., Ludwig van Beethoven - Briefwechsel Gesamtausgabe (München: G. Henle, 1996). 
circumstance needs to be added, first encountered in the $2^{\text {nd }}$ movement of Beethoven's Third Symphony: notation of accidences moves from one instrument to the other and back again, thus forming a closed chain of thematically significant tones $\left(86^{\text {th }}\right.$ bar and onward). This is a hitherto unidentified, new, semantic meaning of otherwise known accidences: Beethoven marks not only the quantity, but also the quality of individual tones, and their importance for the content in equal marks. The judgement on one or the other solution is, of course, left to the performer. The careful reading, paying regard to and proper understanding of the accidences though, leads an interpreter very clearly through Beethoven's music score. The $160^{\text {th }}$ bar of the second movement of Eroica may serve just as an illustration: in fortissimo, all the strings are playing the same, but only the bass line is marked in wedges; the line later climbs over all other strings, to soprano heights: a clear instruction that it is necessary to separately expose bass first, and then follow Beethoven's entirely equivocal semantic instructions.

On principle, Beethoven uses dots in the quieter segments of his compositions but notates wedges in the loud, forte, and fortissimo sections. Of course, there are exceptions, when he notates dots in fortissimo, as in, for example, the first movement of Eighth Symphony - bar I90 (only in the manuscript, obviously), or in the same movement of the symphony in the $3^{\text {rd }}$ bar: notated in the same bar in different instruments are different accidences. However, we also encounter a reverse situation: a forensic examination of the score of the Pastoral Symphony reveals in the $54^{\text {th }}$ bar of the $2^{\text {nd }}$ movement that, despite pp, Beethoven changed the initially written dots above the part of the $\mathrm{I}^{\mathrm{st}}$ violins to wedges. In this case, the author wanted to point to not only the importance of the violins' line but also gave it a technical instruction to be played clearly and audibly enough, despite the dynamics.

In the manuscript of the Sixth Symphony, a particularity is observed exactly with the accidences, that had not so far been admitted in print: Beethoven uses dots and wedges to mark increasing or decreasing intensity in a phrase in a way where, in gradation, he changes dots with wedges (e.g., in the first movement of Eroica in the $466^{\text {th }}$ bar, in Sim- rock's print in ${ }_{1823}$ ), or the other way around (the $\mathrm{I}^{\mathrm{st}}$ movement of the First Symphony in bar I4I - also in Simrock's print in I821. Such a type of passage is also found in the original of the Sixth Symphony in the first movement in the $66^{\text {th }}$ bar, and later in the $188^{\text {th }}$ and $234^{\text {th }}$ bars. If such notation only appeared once, it could be considered an oversight by the author; but as it appears twice in analogue places, it is the author's intent and principle, a law. In neither of Klumpar's transcripts is this hue paid regard!

We are interested, above all, in the differences between Klumpar's clean copy and its copy, and later, of course, also the notations in modern scores that considerably differ from the original and result from the presumption that Beethoven had not been consistent in notating the accidences. In this way, many of these details have unfortunately sunk into oblivion entirely with new prints. Most of the accidences are found in the first movement; they are rarer later on.

\section{Some particularities of the transcript in the National and University Library (NUK)}

Joseph Klumpar, no doubt, has great credit for the authentic transfer of Beethoven's thoughts into the clean copy. As already mentioned, in the manuscript, Beethoven had often only indicated his ideas, which Klumper had to unravel and write out to the detail

The dialectic of his thinking can be read out from Beethoven's records, which is already given evidence by the title itself. The initial title of the symphony, preserved in sketches, was 'Sinfonia caracteristica', later 'Sinfonia pastorella', and finally in the score manuscript: 'Symphonie pastorale Nr. 6 .

In the $\mathrm{I}^{\mathrm{st}}$ movement is an interesting notation of the trill upon the introduction of the reprise: in the $284^{\text {th }}$ bar in the first, 'Leipzig' transcript, the trill has only a single Vorschlag. In the second, 'Ljubljana' transcript, two notated notes are added later; above them, a trill sign is drawn. The same was later also written-in by Beethoven in his manuscript! Somehow left outside this procedure was the first transcript that 
was, however, no longer accessible to Beethoven, as the publisher carried it away with him. A trill with a single Vorschlag has thus appeared in the print, and it stayed this way in all the prints to date. This solution simply does not correspond with original, regardless of the double Nachschlag being incomparably easier to play than the single one (it can be played tied, without a caesura, whereas a single requires a caesura).

Especially interesting is the second movement: at first, it was titled 'Szene am Bach' - 'Scene by the brook'. In this score, however, a crucial nuance is in the very title: the first word 'Szene' ('Scene') is crossed out. The author had most likely wished to avoid any programme determination, which the word 'Szene' undoubtedly holds. He wanted to stress only the spiritual mood that inspires a person in such a moment. The composition is bucolical, has no dramatic moments, therefore every additional programme word is, of course, too much

After the first performance of the symphony, Beethoven was likely discontent with his initial instrumentational decisions in the $2^{\text {nd }}$ movement. He had therefore decided for a colour nuance in the cellos. In the score (first transcript) carried away to Leipzig by the published Härtel in September $18 \circ 8$, there are no respective remarks, just as there are none in the printed orchestral part of the cellos. Entered into the Ljubljana score before the cello part is - while very difficult to read - the remark that fully reads: ' $[D]$ ue Violoncelli', and below it '[Pri]mo e secondo solo Con Sordino. Written in at the bottom side is a very hard to read instruction 'gli Violoncelli tutti coi Bassi. Sadly, the page has edges cut at the bottom, so not much was left from the remark on the bottom margin, but the text can be made out. The deeper meaning of these remarks is also instructive today: Beethoven had tried to restrict too big a tone of the cellos, and had therefore reduced it to only two musicians, and they were forbidden to play with sordino. Thus, the expression 'due soli' does not mean two soloists in the sense of today, but a diminution of a sound previously too rich.

Deserving an individual chapter are the trills and their conclusions, from which Beethoven's perception of their performance can be made out. A nachschlag was usually played at the end of the trill, and is thus usually not notated. Presenting an exception were the cases when the composer wanted to have a melodic end of the trill, if a trill had no continuation (second movement, $33^{\text {rd }}$ bar), or if the trill was followed by a more substantial jump than a second one (e.g., second movement, $86^{\text {th }}$ bar). In this case, the nachschlag had to be notated. Beethoven was highly accurate in notating trills; the modern editions sometimes do not pay precise regard to these instructions, and also write nachschlags where there are none in the manuscript.

In the third movement is the author's demand, unfortunately, overlooked today, that the beginning of the movement be notated in dots in all instruments. In corrections of the first, 'authorised' score, there are dots thickly written in red pencil in the $35^{\text {th }}$ bar in oboe and bassoon parts, just like in the $37^{\text {th }}$ bar in clarinet parts. Typically of Beethoven, dots slowly begin changing into wedges in this part, but it does not essentially change anything, since there are only dots noted in the flute simultaneously.

Most worth mentioning in the fourth movement, apart from dots at the beginning of the movement that illustrate a concealed commencement of the storm much better than wedges, is the change of the part in contrabasses from the $2 \mathrm{I}^{\mathrm{st}}$ bar onward: Beethoven probably realized in performing the symphony, that the contrabasses could not play out the quintuplets; therefore, he changed them to quadruplets, thus creating probably the first impressionist moment in the history of music.

There are no particularities in the fifth movement.

The transcript of Beethoven's Sixth Symphony in the National and University Library in Ljubljana is a precious aid to the understanding of the author's thoughts, expressed in the manuscript, and valuing of the later editions of this symphony. 